\title{
UNA ÓPTICA PICTÓRICA AL PAISAJE
}

\section{LANDSCAPE PAINTING OPTICS}

Enrique Mena García. Universidad Católica de San Antonio. España.

\section{RESUMEN}

Se pretende tener una visión amplia del paisaje dentro de la pintura, un género que surgió con fuerza especialmente después de la época medieval con la entrada de la Edad Moderna en el siglo XV, y consigue su auge en el siglo XVII hasta la llegada de la Escuela de Barbizon y los impresionistas con su "plein air", y que alcanzan un siglo XX polémico, alejado de lo clásico, de vanguardia, que transcurre en una vía paralela el paisaje académico frente a nuevos retos y formas de expresión.

PALABRAS CLAVE: paisaje, plenarismo (plein air), arte, vanguardia, pólders.

\section{ABSTRACT}

It is intended to have a broad view of the landscape in the painting, a gender that emerged strongly especially after the Middle Ages with the entry of the modern age in the fifteenth century, and achieved its peak in the seventeenth century until the arrival of the Barbizon School and the Impressionists with their "plein air", and reaching a controversial twentieth century, away from the classic, avant-garde, set in a parallel track the academic landscape facing new challenges and forms of expression.

KEY WORDS: landscape, plein air, art, avant-garde, polders.

\section{Cómo citar el artículo:}

Mena García. E. (2017). Una óptica pictórica al paisaje. Revista de Ciencias de la Comunicación e Información, 22(1), 31-46.

doi: http://doi.org/10.35742/rcci.2017.22(1).31-46

\section{INTRODUCCIÓN}

En uno de los ocho segmentos titulado "Cuervos" de los que cuenta la película Los Sueños de Akira Kurosawa en 1990, debido al aniversario del fallecimiento de Van Gogh, momento en el que surgieron dos películas más, el director realiza una inmersión en la obra del pintor a través de un espectador, un ejercicio de introspección pleno, donde el público o más bien el personaje que contempla la obra se introduce en un cuadro y obtiene una óptica del paisaje de primera mano, percibe su aire, su ambiente, el momento en el que se pintó, incluso ve a Van Gogh en pleno proceso de creación de la obra "Cuervos en un campo de trigo" (1890). Es una 
óptica del paisaje total, es la posibilidad de indagar en el instante de la creación del mismo. Una fantasía ideal para profundizar en el paisaje.

Nos adentraremos en como el paisaje se consolida en la pintura a lo largo de la historia y como en la actualidad pervive y a la vez se diluye en muchas otras cuestiones para abordarlo. La estructura del artículo de investigación se forma con una introducción a la historia del paisaje para, seguidamente, contextualizar a nivel nacional hasta alcanzar el siglo XX.

Se ha dicho que en occidente el comienzo del paisaje se sitúa en inicios del siglo $X V$, ya que en el Trecento de Lorenzetti no hay continuidad hasta casi un siglo después, por lo que las grandes escuelas de paisaje son septentrionales, la flamenca en el siglo XV, neerlandesa en el siglo XVII, inglesa en el siglo XVIII y XIX, y por último, francesa en el siglo XIX-XX con la de Barbizon, además de los impresionistas (Roger, 2007).

Una naturaleza a veces vista como una visión mítico-religiosa, que puede trasladarnos al carácter totémico de civilizaciones antiguas respecto a las montañas o los árboles, visión que también puede caminar del lado de lo singular, lo extraño, lo sublime, lo bello, lo pintoresco o la grandeza, como características estéticas o experiencias científicas.

\section{OBJETIVOS}

El paisaje es un género que debemos acotar como espectadores, es decir, invita en su percepción a su unidad para generar todo un bloque, donde los elementos dispersos se reagrupan en nuestra mente, que sin duda, debido a los mecanismos de nuestra interpretación y apreciación, las estructuras de percepción naturales, sensibles, culturales, consciente o inconscientemente actúan en cada sujeto formando su juicio estético y formal.

Un objetivo general, dada la cantidad de posibilidades que ofrece el género, con unos existentes subgéneros que abarcan a especialistas en mar, montaña, urbes, etc., es comprender como se ha desgranado el paisaje debido a cada época, su idiosincrasia y como se afronta en la actualidad.

Escribe Javier Maderuelo en su inicio del libro Paisaje y Pensamiento (2006), que ese placer que produce la contemplación del paisaje genera la necesidad de prolongar el recuerdo por medio de la descripción gráfica, pictórica, literaria o fotográfica, teniendo además otros medios de representarlo, donde el paisaje se piensa y reflexiona, acercándonos a su lado filosófico y profundo.

Una naturaleza como fuente inagotable de inspiración, que es superada en su belleza por lo artístico y, como diría Friedrich Th. Vischer, "la belleza de la naturaleza está destinada a ser superada en la fantasía y en el arte" (Maderuelo, 2006). En este sentido Oscar Wilde indicaba que "el arte empieza donde termina la naturaleza" (Wilde, 1995). 


\section{METODOLOGÍA}

\subsection{Concepto}

Ante el título clave en la investigación, el vocablo "Paisaje" en arte se define según la RAE así: "Conocido como pintura o dibujo que representa cierta extensión del terreno". El paisaje, desde el punto de vista artístico, sobre todo pictórico, es la representación gráfica de una Tierra (entiéndase en toda su extensión) que se abre al ojo humano. El paisaje también puede ser el objeto material a crear o modificar por el arte mismo como el Land Art. Este término de paisaje es usado de forma indistinta en campos tan dispares como la biología, la política, la geografía, la cartografía, el urbanismo, etc.; por lo que Javier Maderuelo, dada su ambigüedad, es partícipe de señalarlo como creación de un género de pintura en el arte, cobrando sentido pleno (Maderuelo, 2006).

Aunque en griego no se encuentra ningún término que se aproxime al concepto de paisaje, la retórica griega llegó a destilar dos palabras relacionadas con la idea de "descripción del lugar", topografía y topotesia, que se refieren a "lugar real y "lugar ficticio". Curiosamente, la retórica latina no dispone de ninguno para nombrar estos conceptos y tendrá que recurrir a la locución "descriptio loci", que fue empleada para referirse al "lugar de los hechos" en los debates judiciales. En cambio, en otras latitudes como Japón y particularmente China aparece por primera vez el concepto pleno de paisaje (Maderuelo, 2005).

La palabra "paisaje" aparece ya en algún texto del siglo XVI. Concretamente en el portugués de Francisco de Holanda, Diálogos de Roma (1548), y en autores como Calderón, Gracián, Lope de Vega y Palomino. Así comienza Julio Caro Baroja en el catálogo de Pinturas del Paisaje del Romanticismo Español conllevando una exposición en el Banco Exterior de España (Madrid) en 1985. En el siglo XVII hubo algún paisajista especializado, como Ignacio Iriarte, llegando muchos más en el siguiente siglo XVIII. Para $\mathrm{M}^{\mathrm{a}}$ Ángeles Hermosilla el término es un galicismo del siglo XVIII (heredado, a su vez, del holandés) que significa "pedazo de país" (Hermosilla, 1997).

Y como afirma Maderuelo en su introducción de El paisaje, Génesis de un concepto (2007), pretender ofrecer una definición de paisaje con las debidas condiciones de concisión y universalidad es realmente imposible.

\subsection{Clasificación}

En pintura es tan amplio el concepto de paisaje que cabe distinguir algunos puntos diferenciales en la manera de tratarlo y en ocasiones lo han diferenciado de este modo: El paisaje "cósmico" o "sublime", en el que se presenta la naturaleza de manera salvaje, a veces lugares inexistentes. En esta línea estaría el "paisaje naturalista" reflejando una naturaleza grandiosa y abundante, en la que pueden aparecer fenómenos atmosféricos como en Durero, Elsheimer, Friedrich, etc. Según Remo Bodei, los lugares de lo sublime son las montañas, los océanos, los bosques, los volcanes y los desiertos. Todos ellos, misteriosos, mitológicos, atrayentes de antiguas tradiciones, de leyendas, secretos, etc.; iniciando un largo eclipse en el siglo XX, "pues, lo sublime deja de constituir un tema relevante, tanto en la reflexión 
estética como en las artes" (Bodei, 2011). Aunque, también confirma que lo sublime en esta época de turismo global casi vandálico, se manifiesta de otra manera, como las guerras mundiales, sustitutos de lo sagrado y lo natural, enfocado a lo sublime político de masas con una omnipotencia del jefe dentro de los totalitarismos. Pero, lo sublime se reincorpora en el arte con la pintura americana de Mark Rothko, Barnett Newman, dirigiéndose no a la belleza, evitando prejuicios, sino hacia lo Absoluto, lo sideral, el cosmos (Lyotard, 1999).

Keneth Clark habla de varios paisajes como: el de símbolos, desde la Edad Media, con los salterios, tapices, bestiarios; las obras de Lorenzetti, la influencia bizantina y los primeros flamencos; El paisaje de hechos, con un nuevo sentido del espacio, como en Van Eyck, Pollaiuolo, Piero Della Francesca, A. da Messina, G. David, Patinir, Brueghel, Bellini, H. van der Goes, Vermeer, etc., más reales y sutiles; Los paisajes de fantasía como El Bosco, Grünewald; y el paisaje ideal como los primeros de Giorgione o de Tiziano, con una vegetación y lejanas montañas idílicas, como Carracci, Claude, Poussin, Constable, etc., este último entrando en esa visión natural que comienza a principios del siglo XIX, alcanzando grandes ejemplos en Corot, Courbet, Pissarro, etc. (Clarck, 1971).

Desde otro punto de vista, referido al tema que se representa y no tanto a la manera en que se trata, cabe diferenciar entre paisajes fluviales y marinas, que ofrecen mares, arroyos, ríos, o cascadas, etc., como en Ruysdael; Paisajes estelares o paisajes nubosos, formaciones del clima y condiciones atmosféricas, como en Turner; Paisajes lunares, mostrando la visión de la luna en la tierra o de desconocidos planetas, como Yves Tanguy; Paisajes urbanos, cuyo tema central son las urbes, los Hardscape o paisajes duros, representando mastodónticas ciudades, calles pavimentadas y grandes complejos de negocios o industrias, como Mario Sironi, E. Hopper, etc.; El paisaje aéreo o etéreo, mostrando la superficie terrestre vista desde arriba o desde un punto de vista panorámico bajo como en "Vista y mapa de Toledo" de El Greco; Y por último, el paisaje onírico en composiciones parecidas a los paisajes (generalmente surrealistas o abstractos) que buscan expresar la visión psicoanalítica de la mente como un espacio tridimensional, a veces composiciones de edificios fríos de gran sobriedad y austeridad racional como en Chirico, George Grosz, etc. (Gombrich, 2006).

Escribe RaffaeleMilani que "el nacimiento del paisaje, como conciencia del paisaje en una acepción reciente, moderna, se produce sustancialmente en Italia con la Subida al Monx Ventoux de Petrarca (1336) y con los Efectos del Buen Gobiernoen el campo (mural del Palacio Público de Siena) de Lorenzetti" (Milani, 2006). El historiador Milani clasificaba el paisaje como categoría mental, cultural, y estética. Se han considerado como los primeros relatos alpinistas junto con los de Antoine de Ville en el Monte Aiguille en 1492. Junto con los primeros paisajes en el sentido moderno que han sobrevivido de Lorenzetti (Clarck, 1971. Continúa afirmando Clark que los frescos de Aviñón en 1343 del Palacio de los Papas (Tour de la GardeRobe) son los primeros ejemplos completos de paisajes de símbolos, tanto desde el punto de vista del tema como desde el estilo.

La naturaleza con el renacimiento es "dominada" por el hombre, como ocurre con el paisaje flamenco o neerlandés, cuya presencia del hombre hace que la naturaleza 
no parezca amenazadora. A veces representa un lugar preciso e identificable como en Patinir, Pieter Brueghel el Viejo, etc. Y la naturaleza más típica de Italia, la "colonizada" por el hombre, donde la ha hecho suya. Dentro de este tipo de paisaje puede hablarse del "paisaje clásico", donde se representa una naturaleza ideal y grandiosa. A veces recompuesta para presentarla perfecta. Es tópica la presencia de arquitectura romana, combinada a veces con naturaleza como en la habitual con la llegada del Barroco con Annibale Carracci, Albano, Domenichino, hasta Poussin, etc.

\subsection{Génesis y evolución}

Podemos iniciarnos en el Antiguo Egipto que conserva algunas representaciones paisajísticas esquemáticas en las tumbas de los nobles, grabadas en relieve durante el Imperio Antiguo y pintadas al fresco en el Imperio Nuevo, pasando por un paisaje griego clásico, basado en los escasos textos de obras originales de pintura artesanal y el reflejo que se tiene en la cerámica, así como en la decoración parietal de edad romana, y en mosaicos. También el arte Chino que impulsó el paisaje en el siglo $\mathrm{V}$, que con sus tintas se puede considerar como una rama autónoma de la caligrafía china de la que partió, fundada sobre los cuatro tesoros de la escritura: (pinceles, tinta, tintero y papel).

Durante toda la Edad Media cristiana el paisaje se concibe como una obra divina y su representación hace referencia a su Creador. En la pintura occidental, la representación realista del paisaje comenzó dentro de las obras religiosas del siglo XIII. Las representaciones de la naturaleza serán muy primitivas alcanzando el Trecento de paños dorados. Fue el florentino Giotto di Bondone el primero que abandonando los precedentes modelos bizantinos sustituyó el fondo dorado de las imágenes sagradas por escenarios de la realidad, perspectivas que vemos en sus frescos más conocidos en Padua y Asís. Autores como Boccaccio alabaron su realismo, siendo muchas veces representaciones simples, pero poco a poco, a lo largo de la Baja Edad Media, la atención a esos retazos de naturaleza que aparecían en las escenas sagradas o míticas fue ampliándose, pero su carácter secundario lo revela el hecho de que muchas veces se lo dejaba a ayudantes. Dentro del estilo ítalo-gótico, Ambrogio Lorenzetti superó la representación arquitectónica de su maestro Duccio di Buoninsegna y fue influido también por Simone Martini (VV.AA. 1997). Los frescos de Giotto inducen a algunos historiadores como Kenneth Clark a comenzar la historia del paisaje con su obra, además de los italianos Martini y los Lorenzetti, incluyendo los paisajes de fondo de Fra Angelico o Gentile da Fabriano.

La pintura gótico-flamenca se caracteriza por sus detalles de gran realismo, conseguido en gran medida gracias a la nueva técnica de la pintura al óleo. Un paisaje más urbano con un acentuado interés de representar el plano del fondo en las obras de Van Eyck como la "Virgen del Canciller Rolin" (Panofsky, 1998). "La pura atmósfera de los paisajistas no se ha logrado, sin embargo, fue Van Eyck quién realizó esa conquista sin renunciar a la plasticidad de los menores detalles" (Lothe, 1970). Los primeros paisajes modernos fueron sumamente pequeños, donde Clark suele lanzar la hipótesis de Hubert Van Eyck en torno a 1414-17.

En Flandes, concretamente en Amberes, tiene lugar la primera representación del paisaje independiente, la de Joachim Patinir, cuyas composiciones religiosas o 
mitológicas están totalmente dominadas por la representación realista de la naturaleza, hasta el punto de que la escena es mero pretexto para representar un paisaje panorámico o geográfico, desde un punto de vista muy elevado. En la generación siguiente le seguirán Pieter Brueghel el Viejo y la Escuela del Danubio como en Albrecht Altdorfer o Lucas Cranach el Joven.

El paisaje adquirió autonomía iconográfica en el siglo XVI, en pleno Renacimiento, sobre todo con el arte flamenco y alemán como Alberto Durero que dejó numerosas acuarelas de paisajes. Durero conoce la pintura veneciana quién en sus grabados y xilografías es pionero en mostrar parajes que han sido la mayor de las veces observación directa del natural. Paisajes autónomos que, como los de la escuela del Danubio recogen esa independencia del paisaje todavía de pequeño formato enlazando con los flamencos; (algunos atribuyen el alumbramiento en la obra de A. Altdorfer Landscape with a foodbridge de la National Gallery en 1516).

En su forma idealizada de inspiración clásica, el paisaje es algo que debe atribuirse a Italia, siendo Perugino, maestro de Rafael, uno de los más destacados elaboradores de vastos espacios en los que se situaban los personajes. Por otro lado, será en Venecia, con su luz cambiante sobre las aguas, quien continuará el paisaje como excusa en el fondo de las obras, no siendo todavía su motivo principal. Se esmeraron por lograr realismo reflejando vistas de la laguna, sus calles, monumentos y los fenómenos atmosféricos. Con Giorgione descubrimos a un pintor que goza de libertad en ese Renacimiento muy sujeto a los argumentados temas de encargo, imponiéndose el gusto del pintor, desafiando a las aisladas figuras para irrumpir con las enigmáticas ruinas y oculto tema en "La Tempestad" (1506), que desafía a los exámenes iconográficos de los expertos historiadores. Unos años antes de Giorgione, Leonardo Da Vinci había descrito como representar la tempestad en un cuadro en su famoso Tratado de Pintura (Da Vinci, 2004).

Como Giorgione hay pintores vénetos o próximos a ellos que seguirán con esos motivos paisajísticos, caso de Antonello da Mesina, los hermanos Bellini, Andrea Mantegna, Carpaccio, etc. Lhote diferenciará dos grandes familias de paisajistas: los que se apoyan en el color con todos los matices, contrastes cromáticos (Rembrandt, Van Gogh, etc.), y los que se auxilian en el claroscuro, recurriendo a las variaciones de color con las fuentes de luz (Brueghel, por ejemplo). Unido a este renacer, son los tratados y teorías de poetas y escritores como Dante, Petrarca, Boccaccio, Sacchetti, Filippo Villani o Cennini, o de arquitectos y pintores como L. Battista Alberti y Leonardo Da Vinci los que impulsan el paisaje (Lothe, 1970).

Desde el siglo XV al XVIII, el grabado brilla con luz propia en los países germánicos, Italia, Francia, Flandes...; acrecentando el campo artístico y generando un rico coleccionismo de estampas. En España esta tradición, a pesar de la existencia de focos en Barcelona, Valencia, Mallorca, Madrid, Granada, Santiago de Compostela...ha sido más débil y fragmentada que su homóloga europea, debido a condiciones de tipo sociológico y artístico (Socías, 1997).

Surgirá la visión de los jardines placenteros, apareciendo libros como los de Francesco Colonna (Sueño de Polífilo) y Jacopo Sannazaro (Arcadia), que a inicios del XVI relatan visiones del paisaje y jardines entre sus historias de amor, 
conociendo seguro la Metamorfosis de Ovidio, alcanzando tratados sobre el arte de la jardinería, interesándose los pintores en su esquemáticas composiciones, con esas vistas aéreas, casi panorámicas de jardines palaciegos como Versalles, El Pardo, el Alcázar madrileño, etc. Esto irá unido al interés por la geografía mundial, con el desarrollo de la cartografía, surgiendo tratados geográficos, mapas y vistas topográficas, una moda que con el monarca Felipe II estaba ya más que extendida.

K. Clark escribía sobre Jerónimo Bosch El Bosco afirmando que:

Uno de los motivos por los que son tan convincentes sus fantasías del inconsciente, aun cuando las fábulas del misticismo popular que las inspiraron están olvidadas, es que se basan en la más delicada percepción de la naturaleza. Los fondos del Bosco contienen algunos de los paisajes de hechos más auténticos pintados en Holanda desde los hermanos Van Eyck (Clarck, 1971, p. 46).

En el Barroco sólo de manera lenta y dificultosa el paisaje fue liberándose de lo convencional, de servir de fondo a escenas religiosas, conmemorativas y también a menudo retratos. Este proceso, a lo largo del cual el paisaje finalmente logró adquirir el rango de género pictórico reconocido, con el carácter de dedicación específica, ha quedado reflejado de forma documental, sobre todo en los inventarios de bienes de algunos pintores del siglo XVII" (Agüera, 1997).

El flamenco Rubens pintó al final de su vida algunos cuadros que se cuentan entre la pintura paisajista europea más importante, como en Holanda Ruysdael, que irrumpirá más tarde con un dominio exquisito en los árboles representados así como la inmensidad de nubes tan espesas que cubren a veces dos tercios de sus cuadros. Otras figuras holandesas son Hendrick Goltzius, Carel van Mander, Cornelis Cornelisz, Cornelis Vromm, y Esaias van de Velde considerado el primero en pintar una vista urbana de un lugar concreto, etc.

Se produjo tal especialización que cada pintor se dedicaba a un tipo de paisaje específico (canales, pólders -terrenos ganados al mar-, molinos de viento, estampas invernales, marinas, etc.). Son numerosos los pintores holandeses del siglo XVII reconocidos por sus temas de paisaje, que no detallaremos por no ser motivo transcendente para la investigación, recurriendo algunos, a cortes clasicistas italianizantes, y a veces especializados en animales como las representaciones campestres de Aelbert Cuyp, incluso se desarrolló un sub-género exclusivamente holandés como el cuadro de arquitectura que representaba el interior de las iglesias (Ayala, 1995).

El citado paisaje urbano genera perspectivas muy comunes de ciudades holandesas, con sus casas de ladrillos y las agujas de las iglesias en el horizonte, y entre ellos destaca Johannes Vermeer quién se dedicó sobre todo a la escena de género, como el paisaje urbano de su ciudad, siendo su "Vista de Delft" (1660), considerada por Marcel Proust como "el cuadro más bello del mundo", e inmortalizado en su obra En busca del tiempo perdido. 
Mientras que en el Norte de Europa se desarrollaba con esa amplitud todo tipo de paisajes puros, en el sur seguía precisándose una anécdota religiosa, mítica o histórica como pretexto para pintar paisajes. Se mantendrá cierta relevancia en el título del cuadro y los pequeños personajes perdidos en la naturaleza para dar la clave de la historia representada en lo que a simple vista parece sólo un paisaje. Este tipo fue creado por el clasicismo romano-boloñés, y en concreto por el más destacado de sus pintores, Annibale Carracci, en cuya "Huida a Egipto de Roma" o "El Martirio de San Esteban" tenemos ejemplos.

Esta línea la siguieron los dos grandes paisajistas franceses formados en Italia: Nicolás Poussin y Claudio Lorena, junto a venecianos como Canaletto o su sobrino Bernardo Bellotto. A lo largo de este siglo XVIII estos pintores vénetos se especializaron en el sub-género de las "vedute", perspectivas urbanas que los viajeros extranjeros del Grand Tour veían en sus viajes a Italia y que luego se llevaban como recuerdo a sus países de origen.

Es cierto que atravesamos en el XVIII una de las etapas más apasionantes del paisaje, como el conocido "pintor de toque", una técnica a veces empleada de Francesco Guardi, de pincelada enérgica, no tan meticulosa con el dibujo, de rasgos rápidos, del gusto de los impresionistas más tarde. Más vedutistas los tenemos en Michelle Marieschi, gran competidor de Canaletto y muerto prematuramente, o el predecesor del género Luca Carlevarijs, sin olvidar a Gaspar Van Wittel, padre de uno de los mejores arquitectos de su tiempo, Luigi Vanvitelli.

A finales del siglo XVIII, aparece otra categoría estética que se contrapone no sólo a las normas de lo bello clásico sino también a lo sublime. Esta categoría, que se denominará pintoresco, se caracteriza por fijar la atención en las texturas ásperas y rugosas, en las cosas enraizadas en el suelo, rústicas y campestres, y en motivos de la naturaleza intranscendentes... Realmente la pintura de paisaje no consiguió su total autonomía hasta que el Romanticismo logró colocarla, en plano de igualdad, junto a la pintura de historia, de tal manera que los paisajes puros, sin el apoyo de figuras y sin ninguna pretensión narrativa, llegaron a alcanzar una significación épica (Maderuelo, 2007, p. 24).

El espíritu de la llustración es el gran impulsor del desarrollo del espacio público, del saneamiento y ordenación, tras el derribo de viejas murallas (Álvarez, 1992, p. 108), y antes de inventar paisajes por mediación de la pintura y de la poesía, la humanidad creó los jardines. Destacan los franceses de Le Nôtre y los del inglés William Kent concibiéndolo a imitación de los cuadros "romanos" de Claude Lorena y Gáspard Dughet. Pero, será el jardín japonés el que concentra lo máximo en lo mínimo, muy inspirador para muchos impresionistas y en adelante.

Dos grabadores italianos del XVIII a tener en cuenta con respecto al paisaje serán Giovanni Battista Piranesi y Giovanni Paolo Pannini. Los grabados de Piranesi se exportaron rápidamente a Inglaterra y otros países, a modo de souvenirs del Grand Tour, antecedente del moderno turismo cultural, aunque en el XV gracias a Gutenberg ya se difundían imágenes. Las reproducciones de Piranesi contribuyeron a la formación y desarrollo del neoclasicismo, casi como un mentor de la arqueología 
moderna, descubriendo también los escritores románticos la ruina como elemento esencia del movimiento:

En el siglo XVIII y XIX hay ya especialistas en el paisaje de montaña, como Wolf, Calame, Birmann, Meuron, Richter, Brett, Loppé, entre otros. Se van decantando dos tipos de temas y artistas, por un lado los pintores de imponentes cumbres, de lo pétreo, helado, solitario, voluminoso, aéreo, sublime $y$ de perfiles góticos, $y$, por otro, los de valles, de lo rural, pintoresco, lo singular, de las gentes, costumbres, trajes, labores, casas, de lo riente o la dureza del medio como tal medio. Hay profusión de grabados alpinos y pirenaicos porque hay compradores, viajeros de estilo aún pionero y ya un turismo inicial. Pero hay además un modelo de viajero que lleva a cabo sus notas y apuntes del natural en lugares pintorescos y a veces prefijados como un ritual consagrado. (Martínez de Pisón, 2009, p. 86).

Los paisajes de mar o campo en Inglaterra de William Turner y los renovados efectos de la luz natural en Constable, serán los impulsores del género paisajístico británico. Otros británicos a tener en cuenta son Joseph Wright discípulo de T. Hudson, considerado como el primer pintor que expresó el espíritu de la Revolución Industrial y Thomas Gainsborough, inspirándose en los paisajistas holandeses del siglo anterior. El resto de la pintura dieciochesca carece de originalidad en cuanto al tratamiento del paisaje. Por otro lado, en la pintura romántica alemana destaca Philipp Otto Runge y Caspar David Friedrich, que se centraron en el paisaje de su país.

El paisaje es la línea que se puede aplicar a todo el siglo XIX. En Europa, como se dio cuenta John Ruskin, y expuso el historiador del arte Kenneth Clark, la pintura de paisaje fue la gran creación artística del siglo XIX. Charles Baudelaire defendía abandonar la monotonía de lo cotidiano en 1867, considerando las ventajas de disfrutar de otros paisajes que nos estaban esperando, y es que "el viajero europeo era, por definición, un viajero del norte: un hombre que huía de -la estufa- y del frío y buscaba placer en los países del sol, en los dominios del calor" (VV.AA., 2004).

"Desde que a fines del siglo XVIII, Senefelder descubrió la litografía, hasta comienzos de este siglo, en que todavía grandes artistas la empleaban con originalidad, hay un florecer de los diversos usos de ella, que revolucionan mucho la concepción del paisaje" (VV.AA., 1985). Esta técnica fue pronto empleada para ilustrar libros de viajes e historia.

La gran disparidad de paisajistas hará que simultáneamente en otros puntos del planeta se de esa tendencia paisajista como la Escuela del Río Hudson en la segunda mitad del siglo XIX, representando el valle del río que desembocará en Nueva York y sus montañas.

Pintores de marinas se incrementan en el siglo XIX entre pintores internacionales rusos, americanos, belgas, alemanes, holandeses, etc. Muchos surgidos del periodo romántico especializados en la representación de paisajes alpinos, así como la época Biedermeier, alcanzando después a la Escuela de Barbizon y los Impresionistas. 
Stendhal decía "siempre me han deleitado los paisajes hermosos, por eso he viajado", y es la época romántica cuando se consiguen numerosas descripciones literarias en el momento de los viajeros del Gran Tour, como Byron, Goethe, Lamartine, Chateaubriand, etc.

Con el impresionismo, "la pintura de la felicidad" en palabras de Clark, con unos paisajes de Pissarro, Seurat, Monet, junto con los impulsores de otras tendencias como Gauguin, Van Gogh, o Cézanne, entre otros, se construirá la modernidad del paisaje, junto con esos precedentes de Constable, Turner, Delacorix, etc. El impresionismo con las teorías seudocientíficas del color y sus experimentos y su alejamiento de lo puramente académico, encuentran en el paisaje un estudio continuo. Ya sea el paisajista más realista o poético "un pasaje no está constituido solamente por una sucesión de árboles, de terrenos y de casas, sino por la atmósfera, que se manifiesta en los vapores que diluyen las formas en ciertos puntos y en una bruma sedosa que une los elementos separados, dando al espectáculo su verdadera unidad pictórica" (Lothe, 1971).

\subsection{Una visión nacional}

En la pintura española no abunda el paisaje antes de finales del XIX, ya que se limita a representaciones de interés topográfico o botánico. Excepcional es un cuadro mencionado y que siglos después atrajo la atención de surrealistas y expresionistas: "Vista de Toledo" de El Greco, con los reconocidos edificios entre el tormentoso paisaje de manchas verdes y tonalidades azul-oscuras, aunque sin olvidar su "Laocoonte" o "Vista y Plano de Toledo". En el siglo XVI, según palabras de Maderuelo, Toledo se convirtió en un laboratorio paisajista, interés despertado por pintores de fuera como Joris Hoefnagel o Anton van der Wyngaerde, conocido en España como Antonio de las Viñas o Antón de Bruselas (Maderuelo, 2007).

Los pintores del siglo de Oro español como Ribera o Murillo encontraron en el papel secundario que ofrecía el paisaje hasta esos momentos, una reconducción a un protagonismo mayor, acompañado de escasos pintores como Francisco Collantes, Ignacio de Iriarte, Juan Martínez del Mazo o Benito Manuel Agüero.

Los cuadros con fondos de batallas en España por parte de Maíno, Carducho, Félix Castello, y Orrente serán recogidos como paso al paisaje del XVIII.

En la España del $X X$ los que recurren al verso o la prosa del paisaje son numerosos emblemas de nuestra literatura como Galdós, Lorca, Machado, Alberti, Unamuno, Baroja, Azorín, Aleixandre, entre otros, reconociendo en más de una ocasión que la generación del 98, como decía el filósofo Julián Marías, son los que aprendieron a ver Castilla como el paisaje de la identidad del alma española. Al respecto se dice que muchos paisajes los conocemos y nos lo imaginamos por el poder que tiene de evocarlos, crearlos o recrearlos la literatura en prosa y verso. Incluso podemos afirmar que algunos los ha descubierto la literatura. Pero ha sido la pintura la que los ha construido sobre un soporte plano, de manera diferente en cada época (García, 2007).

El género del paisaje aunque siguió sin cultivarse con particular intensidad, sí apreciamos la recepción del paisaje realista a través de la obra del belga Carlos de 
Haes, del que se hablará más adelante. Agustín Riancho reflejó los paisajes de montaña, lo mismo que la Escuela de Olot se centró en paisajes de esa zona catalana, con su creador Joaquín Vayreda al frente. El impresionismo en España como en el resto de Europa se recibió de manera atenuada, destacando un discípulo de Haes, Darío de Regoyos como un ejemplo cultivador de ese estilo de paisaje, que pasará desde esa España negra de Zuloaga y Solana hasta el impresionismo, puntillismo y el toque naif.

Concluida la guerra de la Independencia en España podemos citar al inglés Locker que con su Vistas de España (documento gráfico y literario), fue el primero en recoger en esos libros de viaje su curiosidad y visión, como las obras literarias de los románticos extranjeros.

Podemos llegar a la conclusión que con la Escuela Barbizon la plenitud va llegando, hasta que el desenfreno se aproxima a finales del XIX, recogiendo el instante preciso de la naturaleza, captando el momento a base de impresiones, que un grupo novedoso en Francia está renovando, y con estos cimientos fuertes, vamos camino de los ya míticos pintores de la luz españoles como Sorolla, Joaquín Mir o Santiago Rusiñol, donde la pintura al aire libre es una vía que fluía desde ese rincón surgido de los Salones de los Rechazados en París. Ya en pleno siglo XX con la Escuela Vallecana y la de Madrid el fluir del paisaje se consolidaría.

Esta Escuela exprimiría esos colores terrosos, sombras, cobaltos, celestes u ocres del paisaje español, más propio de lo castellano, y son aquellos que apuntan al paisaje como esencia pictórica y que merecen ese puesto honorable como es la Escuela Vallecana surgida en torno a 1927, con Benjamín Palencia al frente y fieles al paisaje y que avanzará a la Escuela de Madrid con figuras de la talla de Vázquez Díaz, Ortega Muñoz o Pancho Cossío que corren a la par que las vanguardias que en casos concretos también tratan el paisaje desde otra dimensión como los paisajes algo inhóspitos y de abrumadores espacios de Martínez Novillo, que buscan nuevas interpretaciones.

Esa contemporaneidad pictórica recoge la áridas tierras de cereales de la meseta o campos de castilla de la Escuela madrileña; el arco Mediterráneo cuyas obras de mar son un escaparate en Sorolla, combinados con agrestes parajes o humedales, ofreciendo gamas cromáticas infinitas; y cielos menos luminosos de expresionistas como Solana o Zuloaga.

La pintura contemporánea disolvió la existencia de los géneros, pero dentro de los diferentes "ismos vanguardistas" podemos diferenciar la personalidad del autor y descubrir el campo del paisaje como un género que perdura. Uno de los críticos actuales más relevantes en Murcia, Pedro A. Cruz Fernández, ha dicho en alguna ocasión y desde un sentido intrínseco más profundo, que tanto en el arte como en la vida todo es paisaje, ver las cosas que corresponden a su lugar pero en su conjunto, no segmentadas y fuera de lugar, ya que no tendrían sentido. Nuestra mirada crea paisaje y dice Cruz que: "El paisaje es vida en cuanto que, como tal, es vivido y transportado -como el caso del pintor- a un soporte en el que alcanza auténtico significado" (VV.AA. 2007). 


\section{DISCUSIÓN}

Incidimos, aunque ya sabido, que siempre que hablamos de "paisajistas" lo hacemos en el sentido artístico exclusivamente, ya que podríamos transmutarlo por ejemplo al campo de los geógrafos, donde la figura pensada del paisajista, está ligada al territorio con competencias relacionadas con la botánica, la arboricultura, la silvicultura, la geología, la arquitectura, etc. Se pueden diseccionar en los gestores de paisaje, que trabajan en horticultura, gestión de ámbitos, conservación de la naturaleza y agricultura $y$, por otro, los científicos del paisaje que tienen conocimientos especializados además de algunos citados, en pedología, hidrología y geomorfología. También tenemos a los arquitectos paisajistas, planificadores del paisaje o los técnicos o ingenieros del paisaje que se emplean en el diseño, proyecto, gestión, conservación y rehabilitación del espacio público, la restauración medioambiental, el urbanismo, la conservación histórica, etc.

Alain Roger se inspiró primero en escribir del paisaje en el arte a través del interés por el paisaje literario, sobre todo en escritores cuyas intrigas estuvieran en parte inducidas por paisajes de Flaubert, Huysmans, Zola y Proust (Roger, 2007).

Kant habla con frecuencia de las bellezas de la naturaleza y alaba la "libre belleza" de una flor o de un colibrí. Describe lo sublime en la Crítica del juicio, donde incluye una descripción con osadas rocas, nubes de tormenta, volcanes y altas cascadas, u obras de arte de grandes proporciones como San Pedro del Vaticano o las pirámides del Cairo.

Está claro que existen variedades de paisaje, aún más en la actualidad, donde se difuminan más los paisajes vírgenes por la invasión y desarrollo humano, un mundo natural invadido por lo artificial, creciendo los manipulados por el hombre, como jardines, arquitecturas urbanas, ruinas industriales, campos agrícolas con edificaciones rurales, etc. El arquitecto Josep $\mathrm{M}^{\mathrm{a}}$ Montaner habla de una nueva concepción del paisajismo, teniendo en cuenta lo industrial, sus arquitecturas, los ejes fluviales, infraestructuras de transporte, puertos, canteras, potenciando lo ecológico, una sociedad postindustrial, ligado al calentamiento global, contaminación, agotamiento de recursos, reciclaje urbano, refiriéndose a la interdisciplinariedad del paisaje, que ofrece morfologías distintas, en paisajes encontrados, en ocasiones urbanos, a veces en el territorio, lugares degradados, bien conservados, etc. (Montaner, Hereu y Oliveras, 1994).

El paisaje, como diría Ortega y Gasset:

Es razón vital, la apuesta por un pensamiento humanista cuyo impulso más fuerte, más anhelante, es la unión con la vida, visión estética de la misma, defensa de la inteligencia y conciencia del naufragio. El espíritu humano es el milagro de la perspectiva y del reino de los valores. El paisaje es abundancia de la mirada, milagro que multiplica los panes y los vinos del banquete que celebra el encuentro entre la naturaleza y el hombre (Romero, 1992, p. 73).

El lugar y la atmósfera de un espacio lo determina también un cuadro (u otras artes), según el profesor Martin Seel, donde la pintura no sólo abre un espacio en el espacio, sino que a la vez dispone con sus configuraciones internas del tiempo de su 
contemplación. Según K. Clark "primero se perciben los objetos naturales individualmente, como agradables en sí mismos y símbolos de cualidades divinas. El paso siguiente hacia la pintura de paisaje fue considerar que formaban un todo que la imaginación podía abarcar y que era símbolo en sí de perfección" (Clarck, 1971). Los paisajes no son estáticos y a esto se refiere Martin Seel cuando dice que: No lo son, por una parte, porque el observador puede moverse en ellos, con lo que las perspectivas y las vistas siempre cambian. $Y$ no lo son, por otra parte, porque en ellos siempre hay movimiento: por lo menos de la luz, casi siempre también del aire y de las plantas, de los animales, de los hombres y de los instrumentos que éstos manejan (Seel, 2007, p. 39).

Acaba diciendo José Rueda en su tesis que:

El Paisaje es orden, es uniformidad y variedad, simultáneamente; es un tema susceptible de ser abordado como tal, pero constituye también, sobre todo, una oferta de propuestas plásticas universales. La Naturaleza (lo misterioso de ella radica en su diversidad infinita dentro de la unidad) puede mostrarse como un conjunto caótico de elementos al observador superficial pero siempre puede extraerse, ineludiblemente, un orden absoluto de su aparente confusión (Rueda, 1989, p. 10).

Y es la historia la que construye esa idea de paisaje, dependiendo de cada época, pero más aún, de cada individuo que la entiende de manera diferente, por lo que tiene mucho de verdad lo que dice el pintor Jesús Mari Lazkano cuando afirma que el paisaje se convierte en un lienzo en blanco, una superficie sobre la que proyectarse.

De lo que no se ha hablado es del color como un medio psicológico para dar vida al dibujo, para hacerlo corpóreo. De esto sabe muy bien Kandinsky y su libro De lo espiritual en el arte (1911). La pintura es una aceptación que deriva de la forma sinuosa de la línea y del acercamiento de los colores (pigmentos que da el entorno), esenciales e independientemente del significado de la cosa representada y del proceso de apropiación que el pintor da y que deriva a estilos como la etapa veneciana de Tiziano, Tintoretto o Veronés donde el color coge fuerza respecto a lo que se hacía en ese periodo de tiempo. Incluso Turner en el siglo XIX o Goya son cruciales para lograr esa cumbre del color del impresionismo, y, esto se repetirá con la exaltación del orfismo, fauvismo y expresionismo en el siglo $\mathrm{XX}$.

Unamuno solía decir que el hombre lleva consigo su propio paisaje dentro, reflejo de su alma, por lo que la naturaleza desde el punto de vista psicológico es un elemento de emociones, comportamientos y actitudes intrínsecas de cada uno, por lo que el paisaje cogido de la naturaleza o del urbano ofrece una prospección del alma desde el lado sociológico y psicoanalítico. Y nuestro apartado de discusión alarga la mano a las conclusiones para reflejar ese sentir del paisaje que nos lleva a citar "a cada época su arte y al arte su libertad", lo que sería hoy día un eslogan publicitario de un movimiento, el cual mostraba la filosofía de la Secession vienesa de finales del siglo XIX y que trasladamos a ese vivir el paisaje según el momento. Y para acabar el apartado y en referencia a Unamuno y su primera línea del párrafo anterior, Francisco Flores Arroyuelo indicaba que: 
El paisaje es esa tramoya dramática, plenamente maravillosa, en la que los hombres se mueven y encuentran mientras discurren sus vidas...; hasta que en la época de Rembrandt comienza a dudarse de la existencia de aquel paisaje para considerarse que el paisaje estaba ya en el pintor, era parte de él, hermanado, de ahí la manifestación de que "el paisaje soy yo" (Flores, 2004).

\section{CONCLUSIONES}

Es cierto que hay innumerables escritos sobre el paisaje, libros y tratados que intentan dar su visión. Nos podemos quedar con la idea de Giambattista Bernadis antes de proseguir en la que dice que el paisaje, para un pintor, es antes que nada un mundo interior que encuentra en la naturaleza su espejo.

El paisaje percibido a través del marco, como asomado a ventanas hacia la historia en Zurbarán, Sebastián Vranckx o Velázquez con sus escenas de desenlaces de batallas, o como una mirilla hacia cuadros que representaban escenarios como en Canaletto, o el empleo de ventanas reales para dar juego y entrada de luz en Veermer, hasta emplearla a modo surrealista en Magritte. Esta evolución es solo un ejemplo de como las cosas se transforman pero a la vez perviven de otra manera.

Otra transformación son los personajes de las escenas religiosas que en interiores eran colosales como en Van Eyck pero que posteriormente Patinir o Brueghel el viejo en escenas de exterior fueron encogiendo hasta no estar más que simbolizados por los elementos del paisaje, y de ser sólo parte de un cuadro de historia o de un retrato, saltó a ser un género propio.

En su sentido más amplio, que no podemos dejar de investigar dentro del contexto del paisaje, tendremos siempre la coexistencia de un paisaje contemporáneo propio de cada momento, con las posibilidades que puedan ofrecer las nuevas tecnologías y soportes informáticos, donde continúan artistas con las mismas inquietudes para indagar, canalizar e intercambiar resultados gracias a aquellas interrelaciones geográficas y culturales para asimilar la pintura de paisaje en cada rincón del mundo.

No podemos sin más dejar esta frontera del paisaje abierta, donde el siglo $X X$ se extiende de forma abrumadora al paisaje desde otras esferas, como las oníricas de Chagall; las filmográficas y de cierta soledad de Hopper o Chirico, a los que les marcó el impresionismo y todavía prosiguen en la línea; la velocidad vertiginosa de los futuristas; lo fauve con miembros como Maurice de Vlaminck, Derain o Matisse, precedentes del Jinete Azul con Kandinsky o Franz Marc; las formas geométricas de Klee como en su "Castillo y sol"; el expresionismo abstracto y su forma de abordarlo como una improvisación del jazz en su action painting en Willlem de Koonig; o el informalismo español que no solo es pintura gestual o de signo como en Tàpies, sino que, en la obra gráfica de Chillida por ejemplo, encontramos muchas obras que dialogan con el espacio con obras incluso que adoptan títulos de ciudades; o los que reman contracorriente hacia lo figurativo como Juan Genovés y su "Particulas masivas"; realistas como Antonio López que crean escuela en cualquier academia de cada pueblo, cuyos millones de pintores anónimos nunca dejarán esta vertiente más realista del paisaje, a veces casi costumbrista, otras innovando, pero sin 
alejarse de la más que figuración paisajista. En definitiva, un paisaje que no muere como género, solamente se transforma.

\section{REFERENCIAS}

Agüera-Ros, J. C. (UM) (1997). El paisaje en los inventarios y la obra de algunos pintores Barrocos españoles, Visiones del paisaje. Actas del Congreso Visiones del paisaje, Priego de Córdoba, Universidad de Córdoba.

Álvarez-Sala, D. (1992). La intención paisajista. Catálogo Paisaje mediterráneo, Exposición en Sevilla: Electa.

Ayala-Mallory, N. (1995). La pintura flamenca del siglo XVII. Madrid: Alianza Editorial.

Bodei, R. (2011). Paisajes sublime. Madrid: Siruela.

Clarck, K. (1971). El arte del paisaje. Barcelona: Seix Barral.

Da Vinci, L. (2004). Tratado de Pintura. Madrid: Akal.

Flores-Arroyuelo, F. (2004). La mirada y la lejanía, el paisaje, Con Manolo Avellaneda en el paisaje, Murcia, del 29 de enero al 28 de febrero de 2004, Sala de Exposiciones CAM. Glorieta de España, Comisario: Francisco J. Flores Arroyuelo, Obra Social CAM, Murcia, Nausica.

García-Guatas, M. (2007). Cézanne y el cubismo: preámbulo y epílogo del paisaje moderno, J. Maderuelo, Paisaje y arte, Abada.

Gombrich, E. (2006). La Historia del Art. Madrid: Debate.

Hermosilla-Álvarez, Ma . A. (1997). La visión Impresionista del paisaje en las primeras novelas de Azorín, Visiones del paisaje, Actas del Congreso Visiones del paisaje, Priego de Córdoba, Universidad de Córdoba.

Lyotard, J. F. (1999). Lo inhumano: charlas sobre el tiempo. Buenos Aires: Manantial.

Maderuelo, J. (2005). El paisaje, génesis de un concepto, en Paisaje y pensamiento, Maderuelo, J. (Dir.) y otros (2006), Madrid: Abada Editores S. L.

Maderuelo, J. (2007). Paisaje y arte. Madrid: Abada.

Martínez de Pisón, E. (2009). Miradas sobre el paisaje. Paisaje y Teoría, Madrid: Biblioteca Nueva.

Montaner, J. Ma, Pere-Hereu P., Oliveras, J. (1994). Textos de arquitectura de la modernidad. Madrid: Nerea. 
Panofsky, E. (1998). Los primitivos flamencos. Madrid: Cátedra.

Pinturas del paisaje del romanticismo español (1985). Madrid: Banco Exterior de España.

Roger, A. (2007). Breve Tratado del Paisaje. Madrid: Biblioteca Nueva S. L.

Romero de Solís, D. (1992). El alma del paisaje, Paisaje mediterráneo, Sevilla: Electa.

Rueda-Andrés, J. (1989). El paisaje como principio de posibilidades plásticas inéditas en el lenguaje pictórico. Madrid: Ed. Universidad Complutense de Madrid.

Socías-Batet, I. (1997). Algunas tipologías paisajísticas en la cultura gráfica de la Europa Moderna, Visiones del paisaje, Actas del Congreso Visiones del paisaje, Priego de Córdoba, Universidad de Córdoba.

Toledo-Puche, C., VV. AA. Obras 1964-1998 (2007). Murcia: Galería Romea 3.

Wilde, O. (1995). De Profundis. Madrid: M. E. Editores. 